\title{
Information Infrastructures for Health Care: Connecting Practices Across Institutional and Professional Boundaries
}

\author{
Jørgen P. Bansler \& Finn Kensing
}

University of Copenhagen, Copenhagen,Denmark(E-mail: bansler@diku.dk; E-mail: kensing@citi.ku.dk)

\section{Introduction}

The health care sector is characterized by an increasing shortage of personnel and ceaselessly growing costs caused by the development of new treatment methods combined with increasing demands for treatment that are associated with an aging population and an increase in chronic diseases. Against this backdrop, policy makers, health care professionals and researchers alike have shown an increased interest in innovative systems of care, which can improve communication, coordination, and collaboration among care providers, both in primary care and specialty services (e.g. clinics, hospitals, and emergency departments). Concepts like shared care, integrated care and continuity of care are indicative of an increased interest in creating coherent and effective health care services for patients that require complex-and often long-term-care. Although these concepts are often used in relation to projects seeking to enhance communication, coordination, and collaboration in relation to particular patient groups, they also have bearing on more general visions of reorganizing health care.

Infrastructural arrangements - such as electronic patient records, terminologies, classification schemes, communication standards, accounting systems, and quality systems - play a crucial role in these new models of care, and it is increasingly hard to imagine integrative initiatives that do not have a strong IT component. This raises a multitude of questions about the - actual and imaginedrole and impact of IT and other infrastructure components in the development of patient-oriented, integrated healthcare services.

"Information Infrastructure" has, in general, received a great deal of attention in the IT industry as well as within academia. It has been dealt with in numerous articles in this journal and in major information system journals like e.g. Journal of the Association for Information Systems (Edwards et al. 2009). While several attempts to define the concept of information infrastructure have been made, no 
general definition exists, but rather than propose a new singular definition of information infrastructure, this special issue of Computer Supported Cooperative Work explores different aspects of infrastructures for health care. The four articles highlight how new infrastructures - socio-technical assemblages - simultaneously connect existing practices, influence and change these practices, and create entirely new practices in health care work. Drawing on their own empirical research as well as a review of recent research, Pollock and Williams deal with theoretical and research methodological shortcomings of many infrastructural studies and argue for theoretically informed, multi-site and longitudinal studies. Ellingsen and Røed develop an ANT approach in analyzing an empirical study of the complexity of establishing and sustaining integration between different information infrastructures. Piras and Zanutto focus on personal health records and the cooperative work they are intended to support to reflect upon the necessity of new infrastructures required to connect not only professional settings but also the home environment. Finally, based on an empirical study of medication practices Bossen and Markussen propose the concept of 'ordering devices', which order information, stipulate action, and coordinate interaction across and within social worlds, and achieve this through the flexible support of different kinds of ordering.

Earlier versions of these articles were presented at the second international workshop on Infrastructures for Health Care at the University of Copenhagen, Denmark in June 2009. The purpose of these workshops is to further discussions on current issues and trends related to the integration and coordination of health care practices across institutional, organizational, and professional boundaries. They attract researchers, health care professionals, IT professionals, administrators, and others engaged in the development of infrastructures and new, integrated applications and services for health care.

\section{Thanks to all the reviewers who assured the quality of this Special Issue:}

Tariq Andersen

Ellen Balka

Liam Bannon

Kirsti Berntsen

Claus Bossen

Giorgio De Michelis

Gunnar Ellingsen

Elihu M. Gerson

Jonathan Grudin

Gro Alice Hamre

Anne Marie Kanstrup
Kari Kuutti

Enrico Maria Piras

Neil Pollock

Madhu Reddy

Toni Robertson

Kristoffer Røed

Carla Simone

Cristiano Storni

Lucy Suchman

Ina Wagner

Alberto Zanutto

\section{Reference}

Edwards, et al. (2009). An agenda for infrastructure studies. Introduction to special issue of Journal of the Association for Information Systems, volume 10, pp. 364-374, May 2009. 